\title{
Composite cervical skin and cartilage flap provides a novel large airway substitute after long-segment tracheal resection
}

\author{
Dominique Fabre, MD, Sunil Singhal, MD, Vincent De Montpreville, MD, Benoit Decante, MSc, \\ Sacha Mussot, MD, Olivier Chataigner, MD, Olaf Mercier, MD, Frederic Kolb, MD, \\ Philippe G. Dartevelle, MD, and Elie Fadel, MD
}

\begin{abstract}
Objective: Airway replacement after long-segment tracheal resection for benign and malignant disease remains a challenging problem because of the lack of a substitute conduit. Ideally, an airway substitute should be well vascularized, rigid, and autologous to avoid infections, airway stenosis, and the need for immunosuppression. We report the development of an autologous tracheal substitute for long-segment tracheal resection that satisfies these criteria and demonstrates excellent short-term functional results in a large-animal study.
\end{abstract}

\begin{abstract}
Methods: Twelve adult pigs underwent long-segment $(6 \mathrm{~cm}, 60 \%$ of total length) tracheal resection. Autologous costal cartilage strips measuring $6 \mathrm{~cm} \times 2 \mathrm{~mm}$ were harvested from the chest wall and inserted at regular $0.5-\mathrm{cm}$ intervals between dermal layers of a cervical skin flap. The neotrachea was then scaffolded by rotating the composite cartilage skin flap around a silicone stent measuring $6 \mathrm{~cm}$ in length and $1.4 \mathrm{~cm}$ in diameter. The neotrachea replaced the long segment of tracheal resection, and the donor flap site was closed with a double-Z plasty. Animals were killed at 1 week (group I, $n=4$ ), 2 weeks (group II, $n=4$ ), and 5 weeks (group III, $n=4$ ). In group III the stent was removed 1 week before death. Viability of the neotrachea was monitored by means of daily flexible bronchoscopy and histologic examination at autopsy. Long-term morbidity and mortality were determined by monitoring weight gain, respiratory distress, and survival.
\end{abstract}

Results: There was no mortality during the study period. Weight gain was appropriate in all animals. Daily bronchoscopy and postmortem histologic evaluation confirmed excellent viability of the neotrachea. There was no evidence of suture-line dehiscence. Five animals had distal granulomas that were removed by using rigid bronchoscopy. In group III 1 animal had tracheomalacia, which was successfully managed by means of insertion of a silicon stent.

Conclusion: Airway reconstruction with autologous cervical skin flaps scaffolded with costal cartilages is a novel approach to replace long segments of resected trachea. This preliminary study demonstrates excellent respiratory function and survival in large animals undergoing resection of more than $50 \%$ of their native trachea. Use of cervical skin flaps buttressed with costal cartilage is a promising solution for long-segment tracheal replacement.

Tracheal surgery has evolved rapidly since the first reports by Hermes Grillo in 1965. ${ }^{1,2}$ Tracheal resection is performed for a host of airway diseases, such as postintubation stenosis, local invasion by adjacent cancers (ie, thyroid cancer), or primary tracheal malignancies. ${ }^{3}$ Currently, resection of long segments of trachea is managed by using primary reanastomosis. This approach has limited the length of trachea that can be safely removed. Most reports suggest 4 to $5 \mathrm{~cm}$ of trachea or approximately 8 tracheal rings can be re-

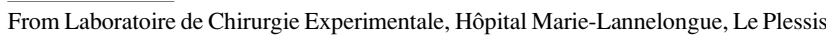
Robinson, France.

Read at the Thirty-fourth Annual Meeting of The Western Thoracic Surgical Association, Kona, Hawaii, June 25-28, 2008.

Received for publication June 22, 2008; revisions received Oct 1, 2008; accepted for publication Nov 9, 2008.

Address for reprints: Dominique Fabre, MD, Centre Chirurgical Marie Lannelongue, Service de Chirurgie Thoracique, Vasculaire et Transplantation Cardiopulmonaire, 133, Avenue de la Résistance, 92350 Le Plessis Robinson, France (E-mail: d.fabre@ccml.fr).

J Thorac Cardiovasc Surg 2009;138:32-9

$0022-5223 / \$ 36.00$

Copyright (c) 2009 by The American Association for Thoracic Surgery doi: $10.1016 /$ j.jtcvs.2008.11.071 moved, and this remains the upper limit of tracheal resection that can be performed without additional maneuvers. Pulmonary hilar release, suprahyoid release, and cervical neck flexion have been used to decrease anastomotic tension. Despite these additional maneuvers, longer segments of the trachea cannot be removed without compromising the safety of the patient. This often results in positive margins and inadequate resections in patients with malignant invasion of the trachea and primary tracheal cancers. Currently, the only available alternative is mediastinal tracheostomy, a procedure that carries a high morbidity and mortality.

After resection of long tracheal segments, a replacement is needed that would alleviate the problems of primary repair. The ideal conduit should be a well-vascularized and autologous tissue that does not incite an immune response. This conduit should also have longitudinal flexibility and transverse rigidity that mimics that of cartilage rings. Furthermore, it should retain the ability to clear secretions. The technique of construction for the neotrachea must be straightforward and the results predictably successful to overcome the issue of long-segment tracheal reconstruction. Conduits 
that have previously used skin flaps and cartilage ribs ${ }^{4,5}$ lack rigidity and often collapse during the expiratory phase. Furthermore, they retain the ability to clear secretions. Two approaches are being used by several investigators to develop a substitute for the long segment of tracheal resection: replacement with prosthetic material and biologic grafts.

Prosthetic conduits have had several limitations. The use of artificial material has been prone to infection, granulation, and airway obstruction. ${ }^{6}$ Conduits that use metallic or silicon stents have problems with inflammatory granulation tissue that ultimately occludes the airway. ${ }^{7-9}$ In repeated studies prosthetic replacement of the trachea results in infection, granulation, obstruction, and migration. These artificial conduits do not incorporate native tissue, which ultimately causes them to fail. An alternative approach using biologic grafts is being tested by several groups. Yu and associates ${ }^{10}$ recently presented their results with a composite radial forearm free flap and prosthesis to replace a long segment of the trachea.

Based on these observations, we have developed the first reproducible autologous tracheal substitute that consistently provides excellent results. We have constructed a conduit using a rotational cervical skin flap that has cartilage rings inserted between the dermal layers and transiently rotated around a stent. We have demonstrated the feasibility and results of this approach in a large-animal model.

\section{MATERIALS AND METHODS Animal Model}

Twelve immunocompetent male large white pigs (17-25 kg) were purchased from Etablissements Cegav (St Marc d'Egrenne, France). They were handled in compliance with the "Guide for the care and use of laboratory animals" (http://www.nap.edu/catalog/5140.html). The animals received care in accordance with French regulations and institutional ethics committee guidelines for animal research. Large white pigs have a typical tracheal length of $10 \mathrm{~cm}$ from the cricoid cartilage to the right upper lobe bronchial segment. Their tracheobronchial anatomy resembles human anatomy, except the right upper lobe bronchial segment branches $2 \mathrm{~cm}$ above the carina.

\section{Preparation for Animal Operations}

Anesthesia was induced with intramuscular ketamine $(100 \mathrm{mg} / \mathrm{kg})$ and maintained with intravenous pentobarbital $(10 \mathrm{mg} / \mathrm{kg}$ bolus, followed by a continuous infusion of $\left.0.1 \mathrm{mg} \ldots \mathrm{kg}^{-1} \ldots \mathrm{min}^{-1}\right)$. The animals were paralyzed with pancuronium $(0.3 \mathrm{mg} / \mathrm{kg})$. After endotracheal intubation, inter-

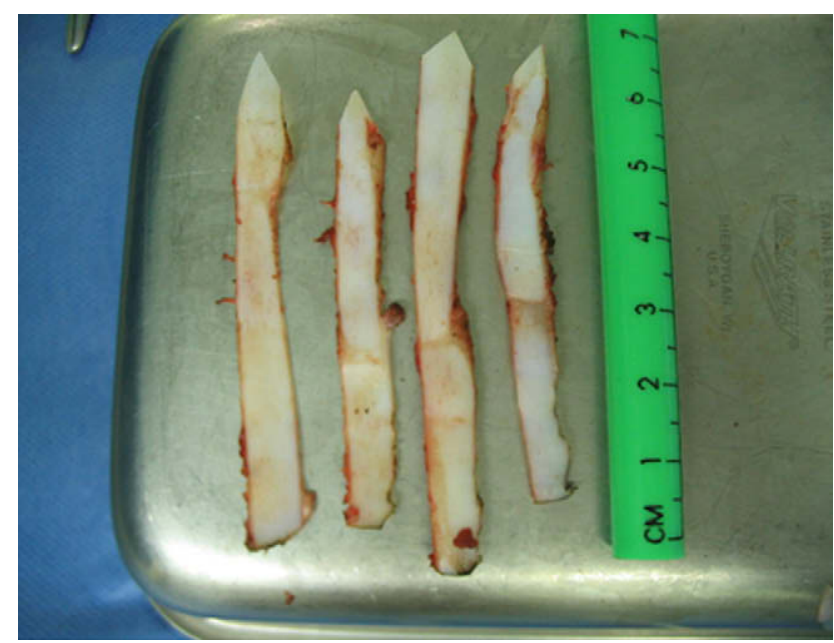

FIGURE 1. Costal cartilages fashioned into tracheal rings. One end of each rectangular cartilage piece was fashioned into the shape of a triangle.

mittent positive-pressure ventilation was provided (MMS 107 ventilator; MMS, Pau, France) at a tidal volume of $15 \mathrm{~mL} / \mathrm{kg}$, with a respiratory rate of 18 cycles/min and a fraction of inspired oxygen of 0.5 . Body temperature was kept constant at $37^{\circ} \mathrm{C}$. Peripheral vascular access was accomplished by placing a 20 -gauge angiocatheter into an ear vein. The adequacy of ventilation and oxygenation was assessed by means of pulse oximetry. Continuous monitoring of cardiac electrical activity was also performed.

\section{Costal Cartilage Harvest}

The animal was placed in a supine position. An incision was made over the most caudal palpable rib. Animals have 13 ribs, each with a costal cartilage along the anterior one fourth of the rib. We exposed the last 3 ribs on the left chest wall and excised the costal cartilage without opening the pleura or violating the internal thoracic artery. These strips of cartilage were divided lengthwise with a no. 15 scalpel. These fragments were cut out to be approximately $2 \mathrm{~mm}$ thick $\times 5 \mathrm{~cm}$ long $\times 5 \mathrm{~mm}$ wide. The end of each cartilage fragment was fashioned into a triangular shape (Figure 1).

\section{Autologous Tracheal Reconstruction}

Once the lateral chest incision was closed, the pig was marked with a rectangle $6 \mathrm{~cm}$ along the length of the trachea and $5 \mathrm{~cm}$ wide centered on the trachea. Three sides of this box were incised at full thickness (Figure 2). This skin flap was lifted up and moistened with a sponge. The trachea was now readily exposed underneath. The thyroid was retracted to the right side. With full neck extension, the trachea could be visualized from the cricoid cartilage to $3 \mathrm{~cm}$ above the carina. The carina could be palpated by means of pretracheal tissue dissection. At this point, the endotracheal tube
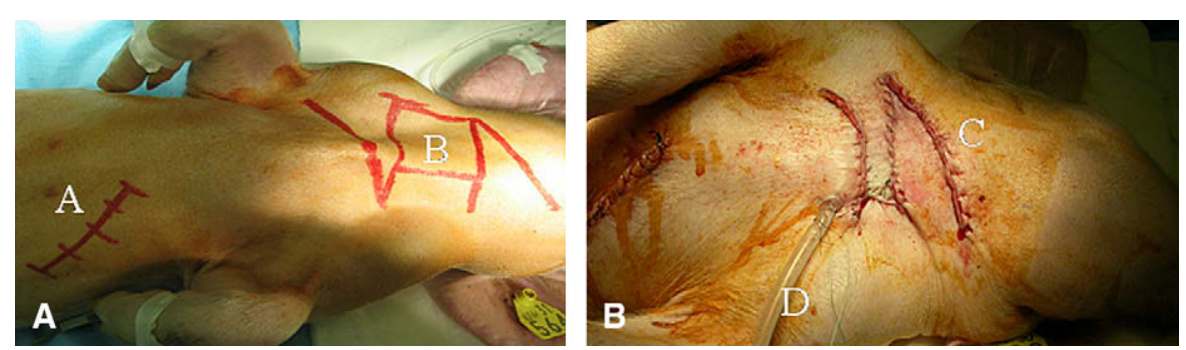

FIGURE 2. Preoperative (A) and postoperative (B) view of the cervical flap and the double-Z plasty. Cervical skin flap: $A$, incision made over the last palpable rib for excision of the costal cartilage; $B$, cervical skin flap used for reconstruction; $C$, coverage of the tracheal reconstruction with a double-Z skin plasty; $D$, cervical drainage. 

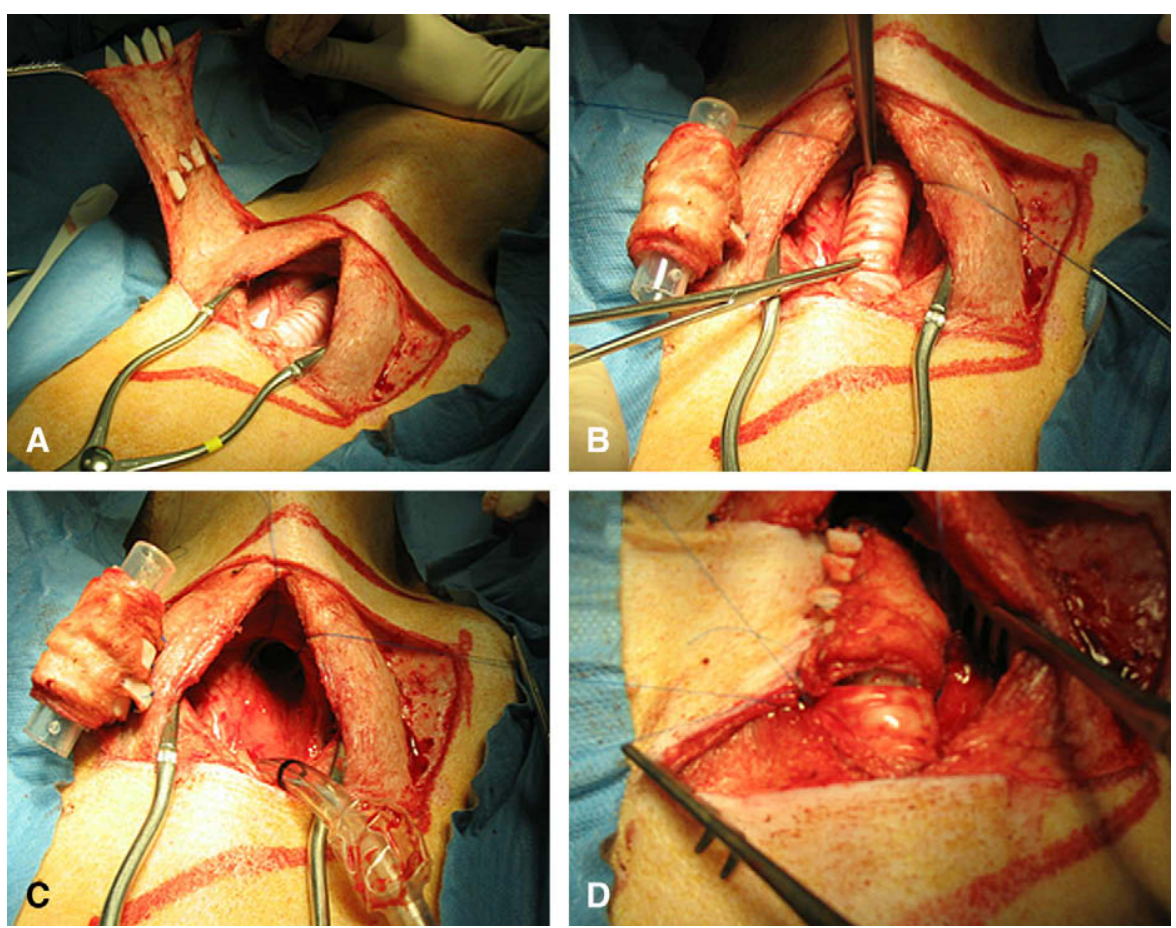

FIGURE 3. Autologous tracheal reconstruction: A, insertion of the fashioned cartilage ribs between the layers of the skin flap; B, the rotational cervical skin flap reinforced with cartilage rings harvested from thoracic ribs rolled around a silicone stent; $\mathrm{C}, 6 \mathrm{~cm}$ of the trachea were then measured and removed with cross-table ventilation; D, proximal and distal anastomoses between the trachea and the reconstruction flap.

was withdrawn to the second tracheal ring. The trachea was measured and then divided $4 \mathrm{~cm}$ above the carina. Cross-table ventilation was instituted to ventilate at the level of the carina. Six centimeters of the trachea were measured and resected, starting slightly below the cricoid cartilage.

The flap was prepared by measuring positions $1 \mathrm{~cm}$ apart along the length of the skin flap. A straight hemostat was used to dissect a plane between the dermal layers at half-centimeter intervals. The preprepared costal cartilages were then inserted at each of these $0.5-\mathrm{cm}$ intervals. Each costal cartilage was secured to the skin-rib sandwich with 4-0 Prolene stitches (Ethicon, Issy-les-Moulineaux, France).

A $6 \mathrm{~cm} \times 14 \mathrm{~mm}$-diameter ribbed silicon stent was laid on the tissue flap. This tissue flap was rolled around the silicone stent and secured with a running 4-0 Prolene stitch. The external layer of the skin becomes the endoluminal layer of the neotrachea, like a mucosa. Thus dermal secretions pour out into the tracheal lumen. The skin graft was sutured closed and planted in the native tracheal position without any further mobilization of the cervical skin flap. Indeed, as shown in Figures 3 and 4, the distance between the flap base and the tracheal bed was limited, allowing free tension anatomoses. A rubber catheter was sutured to the endotracheal tube to facilitate its further replacement. This endotracheal tube was then withdrawn upward through the vocal cords. The cross-table endotracheal tube was removed from the distal trachea intermittently to facilitate placement of the sutures. The neotrachea was reanastomosed in the following fashion. First, the posterior membrane of the proximal and distal anastomoses was secured with a continuous, running 4-0 Prolene suture. Then the cross-table endotracheal tube was removed, and the original endotracheal tube was advanced to lie above the carina. Finally, full-thickness, 4-0 Prolene interrupted sutures were performed on the anterior wall of the neotrachea and native trachea at the proximal and distal anastomoses. As shown in Figures 3 and 4, all the suture lines were covered by the endotracheal silicone stent to avoid a postoperative airway collapse. The suture lines were tested with saline over the sites. Defects were repaired (Figures 3 and 4).
After division of its sternal insertions, the left sternohyoid muscle was then flapped along the length of the longitudinal suture of the neotrachea and secured with a running 4-0 Prolene stitch to separate this suture from the skin suture. A $20 \mathrm{~F}$ drain was placed along the length of the anastomoses. The skin flap site was closed in a Z plasty closure (Figure 2). The length of the buried skin between the base of the flap and the neotrachea is shortened as much as possible to avoid inclusion of dermal cysts. Flexible bronchoscopy was performed at the end of the procedure to examine the tracheal lumen (Figure 5).

\section{Postoperative Care}

Postoperatively, the animals were extubated at the end of the procedure. Animals were placed in cages and fed standard laboratory pig food and water ad libitum. The cervical drain was removed at day 1 . Animals were treated daily with intramuscular cefotaxime $(1 \mathrm{~g})$ and gentamicin $(80 \mathrm{mg})$.

\section{Postoperative Monitoring and Assessment}

The animals were monitored in an animal facility with approved safety measures. The animals were inspected daily for wound healing and respiratory distress. The viability of the Z-plasty closure flap was examined daily. Animal weight gain was measured once a week.

Fiberoptic flexible bronchoscopy. Once a week, the animals were sedated and intubated. Fiberoptic bronchoscopy (Model BF1T240; Olympus Optical Co Ltd, Tokyo, Japan) was performed to examine the anastomosis and viability of the graft. Fiberoptic examinations were performed in each of the following sites on postoperative days 2, 7, 14, and 21: proximal anastomosis, midprosthesis, distal anastomosis, carina, right main bronchus, and left main bronchus (Figure 5). If animals had acute respiratory insufficiency, stridor, or grunting, we immediately performed fiberoptic bronchoscopy. The silicon stent was transparent, which permitted visualization of the flap viability, as well as proximal or distal granulation tissue. 


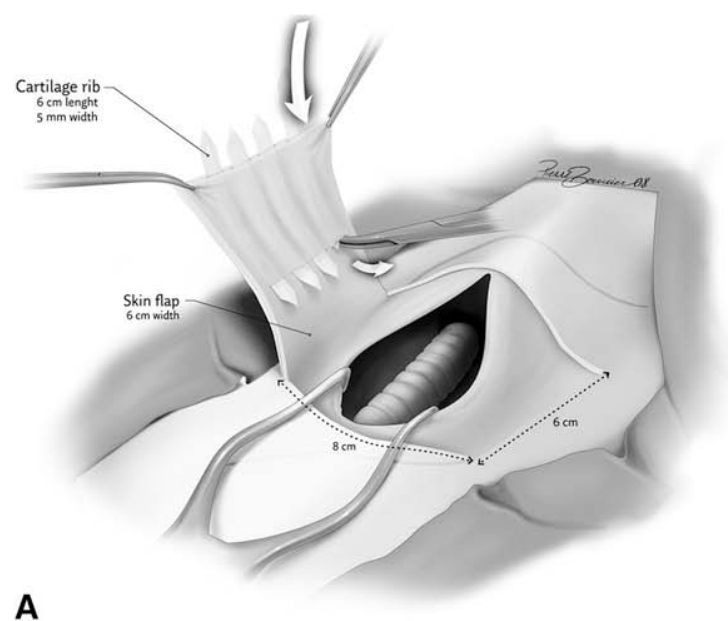

A
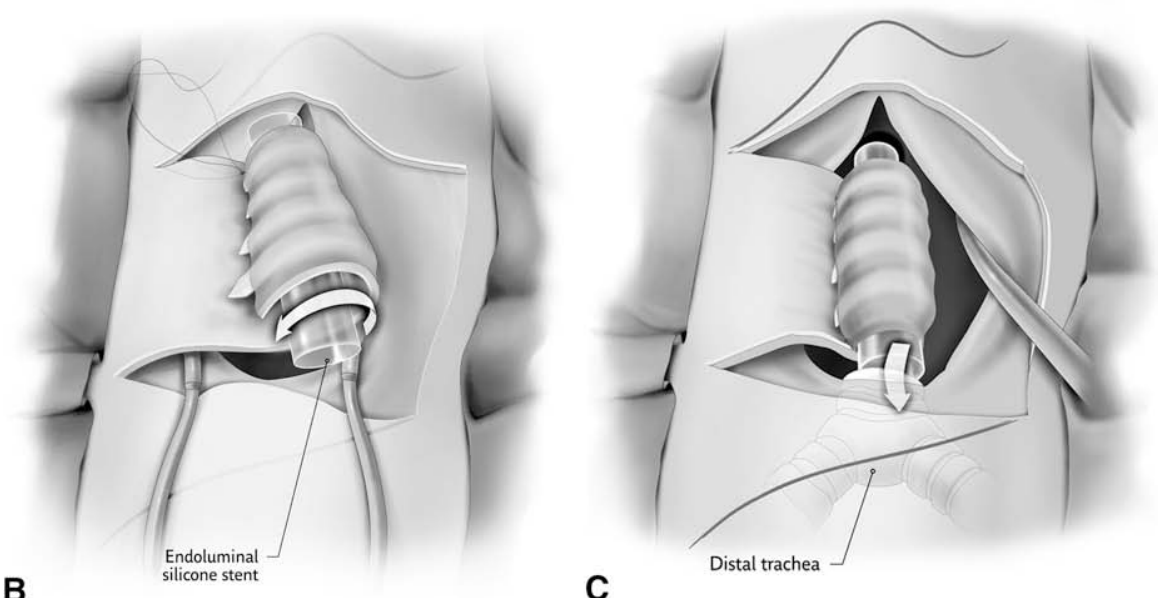

C

FIGURE 4. Diagrams showing the steps of tracheal reconstruction: A, the autologous cervical skin flaps with the cartilage rings inserted between the dermal layers; B, although $6 \mathrm{~cm}$ of the trachea were resected and a cross-table ventilation was instituted to ventilate at the level of the carina, the neotrachea is fashioned by rotating the flap around a silicone stent; $\mathrm{C}$, distal and proximal anastomoses were then performed around the stent and the animal ventilated through a standard endotracheal tube advanced into the stent.

Postmortem autopsy examinations. The animals were killed (barbiturate overdose) at 1 week (group I, $\mathrm{n}=4$ animals), 2 weeks (group II, $\mathrm{n}=4$ animals), and 5 weeks (group III, $\mathrm{n}=4$ ). In group III the stent was removed 1 week before death. All grafts were submitted to postmortem macroscopic and histologic examinations. Any gross evidence of granulation, obstructive lesions, or stent migration was noted during autopsy.
Tissue biopsy and postmortem specimens were immediately fixed in Bouin's fixative and in $10 \%$ buffered formalin, respectively. After being embedded in paraffin, 5- $\mu$ m-thick sections of the trachea were stained with hematoxylin and eosin. The specimens were examined for gross and histologic abnormalities, including ischemia, inflammation, necrosis, and thrombosis.
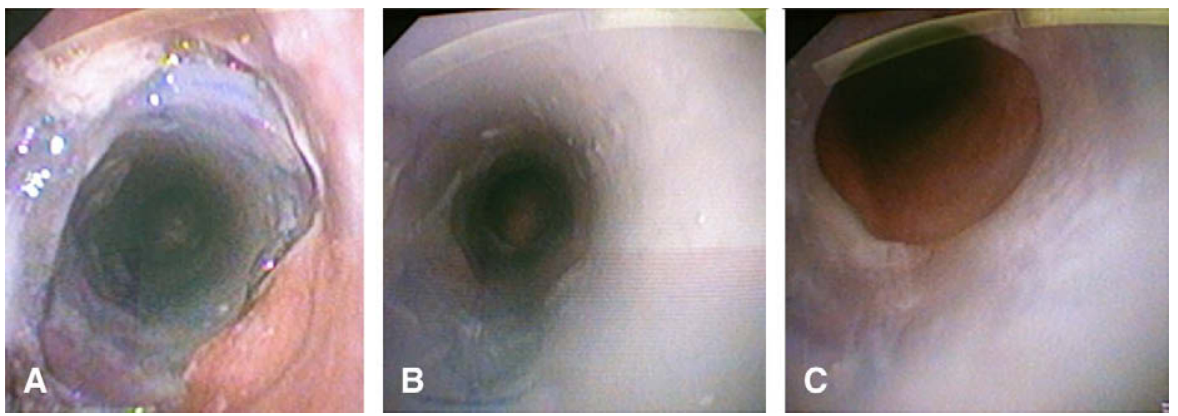

FIGURE 5. Bronchoscopic view of the artificial conduit confirms well-healed tissue in the airway lumen at 1 month: A, proximal anastomosis; B, view of the skin flap inside the silicone stent; $\mathrm{C}$, distal anastomosis. 
TABLE 1. Semiquantitative histologic classification of the tracheal lesions after reconstruction.

\begin{tabular}{ll}
\hline Histologic no. & Histologic description \\
\hline 1 & $\begin{array}{c}\text { Good vascularization of the flap and of the } \\
\text { cartilage ribs (in the absence of inflammation) } \\
\text { Isolated lesions of the epithelium } \\
2\end{array}$ \\
$\begin{array}{l}\text { Partial ischemic necrosis of the flap (loss of nuclear } \\
\text { basophilic chondrocyte or epithelial cell) }\end{array}$ \\
Complete acute necrosis \\
5 & $\begin{array}{l}\text { Primary or secondary infection of the flap (in the } \\
\text { presence of polynuclear cell infiltrate into } \\
\text { the skin flap and cartilage ribs with leukocytic } \\
\text { debris, germs, or both) }\end{array}$ \\
\hline
\end{tabular}

Abnormal tissues along the flap were categorized according to the criteria defined by other groups. ${ }^{11,12}$ The condition of the tracheal reconstruction was assessed according to the following arbitrary semiquantitative 0 - to 5-point scale (Table 1): 1, good vascularization of the flap and the cartilage ribs (in the absence of inflammation); 2, isolated lesions of the epithelium; 3, partial ischemic necrosis of the flap (loss of nuclear basophilic chondrocyte or epithelial cell); 4, complete acute necrosis; and 5, primary or secondary infection of the flap (in the presence of polynuclear cell infiltrate into the skin flap and cartilage ribs with leukocytic debris, germs, or both).

\section{RESULTS}

Overall, this procedure was well tolerated by all the pigs. There were no deaths during the study. Weight gain was appropriate in all animals. On bronchoscopy, there was no evidence of suture-line dehiscence, but a symptomatic distal granuloma attached to the end of the stent was removed in 5 cases by using rigid bronchoscopy. In group III 3 animals tolerated stent removal at 4 weeks. One animal required stent reinsertion because of respiratory distress caused by tracheomalacia.

In group I (Table 2) all the animals were extubated immediately after tracheal replacement. The viability of the skin flaps was confirmed at 1 week by means of bronchoscopy. The proximal and distal anastomoses were clearly visualized, confirming that there was no evidence of flap necrosis. One animal did have progressive dyspnea. Bronchoscopy demonstrated a granuloma attached to the distal edge of the stent. On histologic examination, there was no evidence of inflammation or ischemia in 3 of the 4 cases. Histologic examination of the pig with tracheal granuloma showed isolated lesions of the epithelium and partial necrosis of the cartilage ribs; however, the skin flap remained viable.
TABLE 2. Group I: clinical, bronchoscopic, and histologic outcome at 1 week after tracheal reconstruction.

\begin{tabular}{lllc}
\hline Animal no. & Clinical evaluation & $\begin{array}{c}\text { Bronchoscopic } \\
\text { evaluation at 1 wk }\end{array}$ & Histology \\
\hline 563 & $\begin{array}{c}\text { Subcutaneous } \\
\text { emphysema }\end{array}$ & Small fistula & 1 \\
& & Good & 1 \\
768 & Dyspnea & Good with granuloma & 2 \\
974 & & Good & 1 \\
\hline
\end{tabular}

In group II (Table 3) all the animals tolerated extubation immediately after surgical intervention. The skin flaps were examined at 1 and 2 weeks and appeared viable. The graft in the stented trachea and those in the proximal and distal anastomoses were clearly visualized. In this group 2 animals had progressive dyspnea. Bronchoscopy demonstrated distal granuloma. We performed a bronchoscopic resection of the granuloma. After death, gross examination of the tracheal substitute demonstrated excellent viability of the skin flap with good epithelialization of the cartilaginous ribs into the flap on histology.

In group III (Table 4) all animals were extubated immediately after tracheal surgery. Bronchoscopic examination of the skin flaps at 1 week, 2 weeks, and 1 month demonstrated excellent graft viability. In this group 2 animals had progressive dyspnea. Bronchoscopy demonstrated distal granulomas. We performed a bronchoscopic resection of the granuloma. Three animals tolerated the stent removal at 4 weeks. One animal required stent reinsertion because of respiratory distress caused by tracheomalacia. After death at 5 weeks, gross examination of the graft appeared to have good flap viability with excellent incorporation of the cartilaginous ribs with the skin graft in 3 of the 4 cases (Figure 6). In the animal that had cartilage necrosis with tracheomalacia, gross examination showed a local infection along a cartilage ring, and histologic studies showed partial necrosis of the chondrocytes, with good viability of the remaining flap (Figure 7).

\section{DISCUSSION}

Tracheal surgery remains the mainstay of therapy for several airway diseases. Management of both benign and malignant tracheal diseases often requires long-segment replacement of portions of the trachea. Thoracic surgeons remain challenged by the lack of appropriate substitute

TABLE 3. Group II: clinical, bronchoscopic, and histologic outcome at 2 weeks after tracheal reconstruction.

\begin{tabular}{lccc}
\hline Animal no. & Clinical evaluation & Bronchoscopic evaluation at 1 wk & Bronchoscopic evaluation at 2 wk \\
\hline 924 & Dyspnea & Good with granuloma & Good with granuloma \\
596 & Dyspnea & Good with granuloma & Resection granuloma \\
955 & & Good & Good \\
978 & & Good & Good \\
\hline
\end{tabular}


TABLE 4. Group III: clinical, bronchoscopic, and histologic outcome at 5 weeks after tracheal reconstruction (1 week after stent removal).

\begin{tabular}{|c|c|c|c|c|c|}
\hline \multirow{2}{*}{$\begin{array}{c}\text { Animal } \\
\text { no. }\end{array}$} & \multirow{2}{*}{$\begin{array}{c}\text { Clinical } \\
\text { evaluation }\end{array}$} & \multicolumn{3}{|c|}{ Bronchoscopic evaluation } & \multirow[b]{2}{*}{ Histology } \\
\hline & & $1 \mathrm{wk}$ & $2 \mathrm{wk}$ & $5 \mathrm{wk}$ & \\
\hline 564 & Dyspnea & Good & $\begin{array}{l}\text { Good with } \\
\text { granuloma }\end{array}$ & Granuloma & 1 \\
\hline 846 & & Good & Good & Good & 1 \\
\hline 58 & Dyspnea & Good & $\begin{array}{l}\text { Good with } \\
\text { granuloma }\end{array}$ & Granuloma & 3 \\
\hline 902 & & Good & Good & Good & 1 \\
\hline
\end{tabular}

conduits. At this time, thoracic surgeons resort to primary anastomosis with limited resections and release maneuvers to decrease tension. As Hermes Grillo noted, the current technologies that are being used for tracheal replacement have had a very poor success rate. ${ }^{13}$ However, the opportunity for developing a novel tracheal substitute is now possible with the rapid advancement in tracheal stents, immunosuppression, and our knowledge about skin flaps.

The ideal tracheal substitute should have 5 basic properties: lateral rigidity, vertical elasticity, airtight lumen, continuous internal lining of the respiratory mucosa, and reliable healing. ${ }^{13}$

Artificial prostheses are prone to infection, granulation, and obstruction with poor tissue incorporation. Furthermore, because of the constant exposure of the trachea to the outside environment, infections tend to develop around the anastomosis, causing necrosis, large air leaks, and respiratory insufficiency. These prostheses have been known to erode and develop fistulas into surrounding structures, such as the innominate artery and aorta.

Alternative biocompatible substitutes have also been studied. Allogenic aortic segments have been used in animal models. Neotracheas have been developed from aortic grafts that have been molded for tracheal replacement. These neotracheas have been modified with cartilage rings and demonstrated on a sheep model with some promising results. ${ }^{14-16}$ The neotracheas have been able to somewhat incorporate into the recipient trachea. Martinod and colleagues ${ }^{14-16}$ hypothesized that environmental factors might have triggered recipient cell differentiation. The explanation for this tracheal regeneration is not understood. In contrast, Jaillard and coworkers ${ }^{17}$ have not been able to reproduce these results. In their study epithelial growth was incomplete, and only scattered islets of cartilage formed structurally important tissue. In this series there was a high mortality rate. The tracheal replacement with aortic fresh allograft has been reported in 2 patients by Wurtz and associates after experimental replacement, ${ }^{17,18}$ but the bifurcated silicone stent has not been removed for the 2 patients. Poor vascularization and graft immunogenicity remain the main challenges after these experimental allografts. Various procedures for restoring circulation have been attempted, such as wrapping muscle or omentum around the tracheal substitute. ${ }^{7,8,19}$ Some investigators have attempted to use various vascular growth factor to improve blood supply to the grafts. ${ }^{20}$ Pretreating tracheal allografts has been used with limited success. ${ }^{9}$ Cryopreservation reduces acute rejection ${ }^{21}$; however, the allograft ultimately succumbs to chronic rejection with vascular thrombosis and degeneration. ${ }^{22}$

Several groups have reported the potential use of tracheal segment transplantation. In our institution we have described a technique to transplant the entire trachea, carina, and main stem bronchi. ${ }^{11}$ We have been able to preserve the vascularization to the transplanted segment of the airway. In human subjects a short human tracheal segment (pharyngolaryngotracheal segment) has been transplanted with 40-month follow-up. ${ }^{23}$ However, this approach has been limited by challenges with immunosuppression and
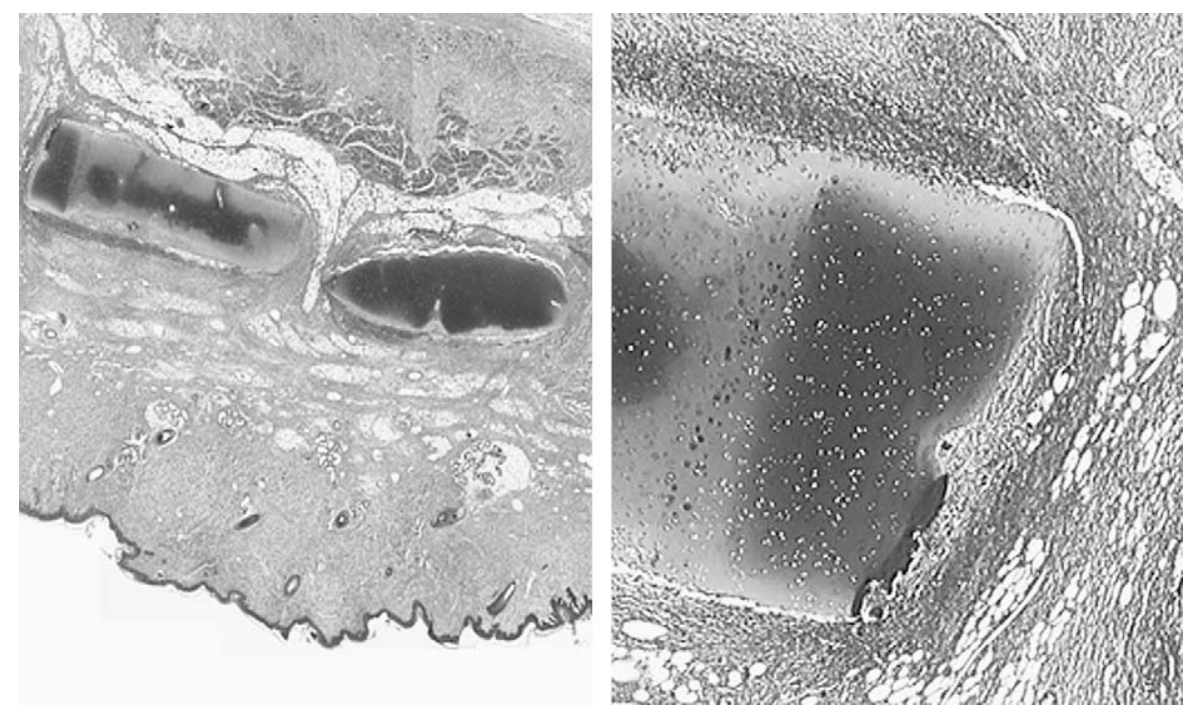

FIGURE 6. Gross examination of the explanted neotrachea at 5 weeks. 


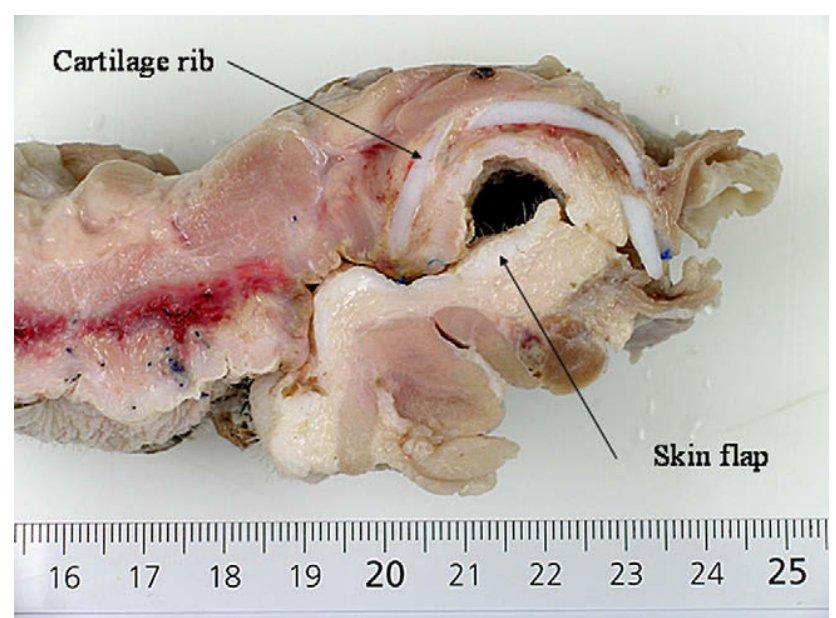

FIGURE 7. Histologic examination of the artificial conduit at 5 weeks demonstrates good viability.

technical difficulties. Tracheal bioengineering with biodegradable matrices with autologous stem cells have been introduced. ${ }^{24-27}$ However, there has been no ultimate tissue-engineered tracheal prosthesis that has been readily available and technically simple to use. ${ }^{19}$

In 1959, Serrano and colleagues ${ }^{28}$ inserted a series of bilateral hemirings of cartilage carved from the costal arch to provide support to skin that was finally closed anteriorly. In 1964, Grillo and associates ${ }^{29}$ developed a staged repair of the cervical trachea to replace a cervical tracheal segment. A cutaneous tube was formed in stages and supported by polypropylene rings inserted between the dermis and the attached platysma muscle. The cervical trachea was reconstructed experimentally by forming a cutaneous trough supported by cartilage or plastic rings. Staged closure of the trough was performed on dogs. ${ }^{30}$

A tracheal reconstruction with a tubed radial forearm graft around a stent has been described by Beldholm and coworkers. ${ }^{4}$ The stent provided stability and a patent airway. To our knowledge, only 1 patient has ever been treated successfully with a long-segment replacement $(6.5 \mathrm{~cm})$ of his trachea with a composite radial forearm free flap and prosthesis. ${ }^{10}$ In this case a 63 -year-old woman was treated with a conduit composed of a radial forearm free flap lined with a composite PolyMax mesh (Synthes, Paoli, Pa) and Hemashield vascular graft (Boston Scientific, Natick, Mass) for rigid support. At 6 months' follow-up, the patient had normal swallowing and preoperative voice quality and a patent nonstented airway. This approach of using a vascularized autogenous tissue flap as a tube after circumferential resection seems to be the most promising approach.

This article presents a novel approach to developing a neotrachea by using autologous tissues with an independent blood supply in a 1-stage surgical procedure. The 5 basic properties desired for an ideal long tracheal substitute were achieved. For lateral rigidity, we used cartilage ribs. For vertical elasticity, we used a cervical skin flap. To maintain the airtight lumen, we used an endoluminal stent that could be removed at a later date. We chose a pedicled flap because it is more reliable than a free flap and avoided the need for a microvascular anastomosis. The flap provided sufficient blood supply for neovascularization of the cartilaginous rib fragments. The size of the cervical flap depends on the length of the trachea to replace. The width of the cervical skin flap should not exceed $150 \%$ of the length of the flap. Animals that had wider flaps had airway obstruction (data not shown).

This surgical procedure can be readily reproduced. We have been able to consistently replace more than $50 \%$ of the trachea with good long-term outcomes. This experimental model is relatively easy to perform. The tissues remain viable at 1,2 , and 4 weeks. Gross examination of the tracheal reconstruction demonstrates viability of the skin flap with good incorporation of the engineered composite graft of the cartilage rib fragments into the flap (Figure 6).

There are limitations to this neotrachea model. First, there remains the risk of stent obstruction caused by mucus plugging during the first several days after the procedure. Fiberoptic bronchoscopy must be used judiciously to maintain the patency of the airway during this period. The pressure exerted by the endoluminal stent can lead to tissue inflammation, ischemia, and granulation. Granulation tissue has the potential to cause luminal stenosis or obstruction. Another limitation to this cervical flap is the difficulty for reproduction in human subjects. Indeed, the cervical skin flap is probably not suitable in clinical practice because the cervical skin in human subjects is less extensive than that in pigs, in which the neck area is larger and shorter. We plan to use a free skin flap with its own arterial and venous vascularization. The blood supply to this free flap will be carried by performing arterial and venous microvascular anastomoses with a cervical vascular pedicle. In human subjects it can be a free forearm skin flap pedicled on the radial artery and vein. These vessels could then be anastomosed to the internal thoracic artery and vein.

In conclusion, we present the first described animal model for tracheal resection and replacement with an autologous conduit constructed from costal cartilages and cervical skin flaps. This model is relatively simple and reproducible. The experimental model has excellent short-term good viability. Further studies evaluating long-term results are still warranted. Follow-up of 5 or 6 months after stent removal is necessary to definitely declare the technique a success.

\section{References}

1. Grillo HC. Circumferential resection and reconstruction of the mediastinal and cervical trachea. Ann Surg. 1965;162:374-88.

2. Grillo HC. Tracheal replacement. J Thorac Cardiovasc Surg. 2003;125:975.

3. Macchiarini P. Primary tracheal tumours. Lancet Oncol. 2006;7:83-91. 
4. Beldholm BR, Wilson MK, Gallagher RM, Caminer D, King MJ, Glanville A. Reconstruction of the trachea with a tubed radial forearm free flap. J Thorac Cardiovasc Surg. 2003;126:545-50.

5. Olias J, Millan G, da Costa D. Circumferential tracheal reconstruction for the functional treatment of airway compromise. Laryngoscope. 2005;115:159-61.

6. Villegas-Cabello O, Vazquez-Juarez JL, Gutierrez-Perez FM, Davila-Cordova RF, Diaz-Montemayor C. Staged replacement of the canine trachea with ringed polyethylene terephthalate grafts. Thorac Cardiovasc Surg. 1994;42:302-5.

7. Dodge-Khatami A, Niessen HW, Koole LH, Klein MG, van Gulik TM, de Mol BA. Tracheal replacement in rabbits with a new composite silicone-metallic prosthesis. Asian Cardiovasc Thorac Ann. 2003;11:245-9.

8. Pearson SE, Rimell F, Stelow EB, Pernell K. Tracheal reconstruction with a synthetic material in a porcine model. Ann Otol Rhinol Laryngol. 2001; 110:718-22.

9. Lenot B, Macchiarini P, Dulmet E, Weiss M, Dartevelle P. Tracheal allograft replacement. An unsuccessful method. Eur J Cardiothorac Surg. 1993;7: 648-52.

10. Yu P, Clayman GL, Walsh GL. Human tracheal reconstruction with a composite radial forearm free flap and prosthesis. Ann Thorac Surg. 2006;81:714-6.

11. Macedo A, Fadel E, Mazmanian GM, de Montpreville V, German-Fattal M, Mussot S, et al. Heterotopic en bloc tracheobronchial transplantation with direct revascularization in pigs. J Thorac Cardiovasc Surg. 2004;127:1593-601.

12. Macchiarini P, Lenot B, de Montpreville V, Dulmet E, Mazmanian GM, Fattal M, et al. Heterotopic pig model for direct revascularization and venous drainage of tracheal allografts. Paris-Sud University Lung Transplantation Group. J Thorac Cardiovasc Surg. 1994;108:1066-75.

13. Belsey RH, Valentine JC. Cylindromatous mucous-gland tumours of the trachea and bronchi: a report of three cases. J Pathol Bacteriol. 1951;63:377-87.

14. Martinod E, Zegdi R, Zakine G, Aupecle B, Fornes P, D'Audiffret A, et al. A novel approach to tracheal replacement: the use of an aortic graft. J Thorac Cardiovasc Surg. 2001;122:197-8.

15. Martinod E, Seguin A, Pfeuty K, Fornes P, Kambouchner M, Azorin JF, et al. Long-term evaluation of the replacement of the trachea with an autologous aortic graft. Ann Thorac Surg. 2003;75:1572-8.

16. Martinod E, Seguin A, Holder-Espinasse M, Kambouchner M, DuterqueCoquillaud M, Azorin JF, et al. Tracheal regeneration following tracheal replacement with an allogenic aorta. Ann Thorac Surg. 2005;79:942-9.
17. Jaillard S, Holder-Espinasse M, Hubert T, Copin MC, Duterque-Coquillaud M, Wurtz A, et al. Tracheal replacement by allogenic aorta in the pig. Chest. 2006; 130:1397-404.

18. Wurtz A, Porte H, Conti M, Desbordes J, Copin MC, Azorin J, et al. Tracheal replacement with aortic allografts. N Engl J Med. 2006;355:1938-40.

19. Kim J, Suh SW, Shin JY, Kim JH, Choi YS, Kim H. Replacement of a tracheal defect with a tissue-engineered prosthesis: early results from animal experiments. J Thorac Cardiovasc Surg. 2004;128:124-9.

20. Behrend M, Kluge E, Schuttler W. On the use of unsealed polypropylene mesh as tracheal replacement. ASAIO J. 2006;52:328-33.

21. Murakawa T, Nakajima J, Motomura N, Murakami A, Takamoto S. Successful allotransplantation of cryopreserved tracheal grafts with preservation of the pars membranacea in nonhuman primates. J Thorac Cardiovasc Surg. 2002;123:153-60.

22. Moriyama H, Sasajima T, Hirata S, Yamazaki K, Yatsuyanagi E, Kubo Y. Revascularization of canine cryopreserved tracheal allografts. Ann Thorac Surg. 2000; 69:1701-6.

23. Strome M, Stein J, Esclamado R, Hicks D, Lorenz RR, Braun W, et al. Laryngeal transplantation and 40-month follow-up. N Engl J Med. 2001;344:1676-9.

24. Macchiarini P, Walles T, Biancosino C, Mertsching H. First human transplantation of a bioengineered airway tissue. J Thorac Cardiovasc Surg. 2004;128:638-41.

25. Kojima K, Bonassar LJ, Roy AK, Vacanti CA, Cortiella J. Autologous tissue-engineered trachea with sheep nasal chondrocytes. J Thorac Cardiovasc Surg. 2002; 123:1177-84.

26. Kojima K, Ignotz RA, Kushibiki T, Tinsley KW, Tabata Y, Vacanti CA. Tissueengineered trachea from sheep marrow stromal cells with transforming growth factor beta2 released from biodegradable microspheres in a nude rat recipient J Thorac Cardiovasc Surg. 2004;128:147-53.

27. Kojima K, Vacanti CA. Generation of a tissue-engineered tracheal equivalent Biotechnol Appl Biochem. 2004;39:257-62.

28. Serrano A, Ortiz-Monasterio F, Andrade-Pradillo J. Reconstruction of the cervica trachea. Reconstruction of the cervical trachea. A technique to obtain a permanently patent airway. Plast Reconstr Surg. 1959;24:333-40.

29. Grillo HC, Dignan EF, Miura T. Extensive resection and reconstruction of mediastinal trachea without prosthesis or graft: an anatomical study in man. $J$ Thorac Cardiovasc Surg. 1964;48:741-9.

30. Grillo HC, Dignan EF, Miura T. Experimental reconstruction of cervical trachea after circumferential resection. Surg Gynecol Obstet. 1966;122:733-8. 